\title{
Hydrophobic and anticorrosion properties of thin phosphonate- siloxane films formed on a laser textured zinc surface ${ }^{1}$
}

\author{
G.V. Redkina,*(i) A.S. Sergienko and Yu.I. Kuznetsov(i) \\ A.N. Frumkin Institute of Physical Chemistry and Electrochemistry, Russian Academy of \\ Sciences, Leninsky pr. 31, 119071 Moscow, Russian Federation \\ *E-mail: GVRedkina@mail.ru
}

The effect of preliminary laser treatment of zinc surface and its subsequent heating on the anticorrosion and hydrophobic properties of the layers formed in solutions of sodium dodecylphosphonate (SDDP) and trialkoxysilanes (TAS), i.e. vinyltrimethoxysilane (VTMS) or $n$-octyltriethoxysilane (OTES), has been studied. The polymodal roughness of the zinc surface resulting from laser and heat treatment allows one to achieve its superhydrophobization upon layer-by-layer passivation with SDDP and TAS as well as to increase the protective properties of the thin films formed by them. Apparently, the surface morphology obtained by such treatment provides better adhesion of the first phosphonate layer. In combination with a strong siloxane network in the top layer, this determines the high protective and hydrophobic properties of the coatings and their stability over time. The most effective is layer-by-layer passivation of zinc in SDDP and OTES solutions with preliminary laser texturing of the surface, which allows one to obtain resistant coatings with high protective and hydrophobic properties in a humid atmosphere. In the presence of OTES, which is more hydrophobic than VTMS and has a relatively long alkyl, a stable highly ordered siloxane layer is formed on the zinc surface, which is capable of blocking existing defects in the film formed by the chemisorbed alkylphosphonate.

Key words: zinc, passivation, corrosion inhibitor, alkylphosphonates, trialkoxysilanes, laser treatment, superhydrophobicity.

Received: November 16, 2020. Published: December 9, 2020

doi: $\underline{10.17675 / 2305-6894-2020-9-4-23}$

\section{Introduction}

Currently, the protection of metals from corrosion by modifying their surfaces with various organic compounds capable of forming self-assembled monolayers (SAM) is a relevant direction in anticorrosion science and practice. Higher phosphonic and carboxylic acids, their salts and silanes, which are often used to obtain SAM, are widely known as corrosion inhibitors (CI) of various metals [1-8]. Especially noteworthy among them are alkylphosphonic acids $\mathrm{CH}_{3}\left(\mathrm{CH}_{2}\right)_{n} \mathrm{PO}_{3} \mathrm{H}_{2}$ (AP) which, due to the presence of a hydrophobic alkyl and a reactive phosphonic group in the molecule, are strongly adsorbed on the surfaces of metals and their oxides to form well-ordered layers possessing hydrophobic and

\footnotetext{
${ }^{1}$ This work was supported by the Russian Foundation for Basic Research (Grant No. 20-33-90012 "Formation of hydrophobic coatings by alkylphosphonates and trialkoxysilanes on zinc and galvanized steel for their corrosion protection.")
} 
anticorrosion properties $[1,5,7]$. As some researchers note, the SAM formed by AP are more strongly bound to the oxidized metal surface and are characterized by higher density, ordering and stability compared to layers of higher carboxylic acids or silanes $[5,9,10]$.

Numerous studies of the specific features of surface modification of metals and alloys with AP, including the treatment for increasing their corrosion resistance, were carried out mainly on steel, titanium and aluminum [5,7, 10-14]. This method of corrosion inhibition has been little studied for zinc and zinc coatings, although it can successfully compete with toxic chromate treatment that does not meet the modern environmental standards $[15,16]$.

The stability and protective properties of alkylphosphonate SAM on various metals depend on the conditions of their application (solution composition, temperature and duration of treatment and drying, preparation method, etc.), the structure of the AP molecule (for example, the length of the hydrocarbon radical), morphology and chemical state of the surface (roughness, presence and composition of the oxide film) [13, 14, 17-21]. Some regularities of zinc passivation by alkylphosphonates were previously studied by us for sodium salts of decyl- and dodecylphosphonic acids (SDDP) as examples $[19,21]$. This passivation treatment of zinc increases its corrosion resistance, both in a chloride-containing aqueous solution and in a humid atmosphere. However, the resulting phosphonate films are not effective enough for long-term protection of zinc against corrosion or under more severe conditions, for example, in a salt spray.

Along with the selection of the optimal conditions and passivation methods, the inhibitory efficiency of AP and their salts can be increased by combining them with other CI. For this purpose, suitable candidates are alkyltrialkoxysilanes with general formula R$\left(\mathrm{CH}_{2}\right)_{n}-\mathrm{Si}-\left(\mathrm{OR}^{\prime}\right)_{3}$, where $R$ is an organofunctional radical and $R^{\prime}$ is a readily hydrolyzable alkoxy (methoxy, ethoxy, acetoxy) group. Along with low toxicity, they are also capable of self-assembly on the surfaces of many metals, including zinc, that gives it a number of valuable properties, for example, hydrophobic or superhydrophobic, anticorrosion and adhesive ones [22-27]. The corrosion inhibition of a metal by organosilanes is due to their interaction with the surface hydroxyl groups of metals leading to the formation of - $\mathrm{Si}-\mathrm{O}-$ Me covalent metallosiloxane bonds and polycondensation of neighboring molecules in the surface siloxane layer [2]. Such self-assembling siloxane nanolayers can significantly inhibit the dissolution of zinc in chloride- and sulfate-containing media and under atmospheric conditions $[8,28]$. However, they do not completely suppress corrosion, as noted in [28].

The possibility of increasing the protective properties of layers formed on zinc in the presence of SDDP by trialkoxysilanes (TAS) with various structures, including using the method of layer-by-layer passivation, was demonstrated by us in [29]. It was shown that the efficiency of inhibition of zinc corrosion in a chloride-containing solution and in a humid atmosphere is higher with a combination of SDDP with TAS than with the individual CI. In this case, the sequence of their formation and the structure of TAS have a great influence on the protective properties of the thin films thus obtained. Treatment of air-oxidized zinc in solutions of SDDP with TAS hydrophobizes its surface. However, the contact angle $(\Theta)$ characterizing its wettability with water does not exceed $106 \pm 4^{\circ}$. To obtain a 
superhydrophobic coating in an CI solution, i.e. with $\Theta \geq 150^{\circ}$, and, consequently, to enhance its protective properties, special preparation of the metal surface is required to give it the necessary microstructural roughness.

Among the many methods of creating a complex morphology of metal surfaces (anodizing, electrodeposition, etching, sol-gel technology, hydrothermal treatment), laser treatment has recently attracted the attention of researchers. This method of changing the roughness is based on the physical processes of the formation of complex two- and threedimensional micron- and nanometer-scale structures on the surface by exposure to laser pulses of various intensities and durations [30]. Laser treatment of the surface of some metals with subsequent heating or adsorption of organic substances increases their corrosion resistance in chloride-containing solutions. For example, it was shown in [31] that after treatment with a nanosecond pulsed laser the copper surface is hydrophilic, but after two hours of heating at $150^{\circ} \mathrm{C}$ it becomes superhydrophobic $\left(\Theta>155^{\circ}\right)$ and acquires anticorrosion and self-cleaning properties. A similar transition of a superhydrophilic surface to a superhydrophobic one with $\Theta>158^{\circ}$ due to a combination of laser and heat treatments was observed on the $\mathrm{Mg}-9 \mathrm{Al}-1 \mathrm{Zn}$ alloy [32]. Using the results of potentiodynamic polarization measurements and spectroscopy of electrochemical impedance, they showed an increase in the corrosion resistance of the magnesium alloy in $3.5 \% \mathrm{NaCl}$ solution with an increase in $\Theta$. It is also possible to achieve the superhydrophobic state of a laser textured metal surface by chemisorption of a hydrophobic agent. In [33], laser treatment with subsequent modification with fluorooxysilanes with low surface energy was used to create superhydrophobic coatings on an aluminum-magnesium alloy, which increased its resistance to pitting corrosion in $\mathrm{NaCl}$ solution. At the same time, we could not find publications on such studies on zinc or zinc coatings.

In this regard, the purpose of this work was to study the effect of preliminary preparation of the zinc surface using laser treatment and subsequent heating on the anticorrosion and hydrophobic properties of the layers formed in the presence of SDDP and trialkoxysilanes.

\section{Experimental}

\subsection{Materials}

The studies were carried out on zinc samples with a $\mathrm{Zn}$ content of $99.975 \%$ where the content of impurities ( $\mathrm{Fe}, \mathrm{Al}, \mathrm{Cu}, \mathrm{Sn}, \mathrm{Pb}, \mathrm{Cd}, \mathrm{As}$ ) was up to $0.025 \%$. We used sodium dodecylphosphonate $\left(\mathrm{CH}_{3}\right)_{12}-\mathrm{PO}(\mathrm{ONa})_{2} \quad(\mathrm{SDDP})$ and TAS - vinyltrimethoxysilane $\mathrm{H}_{2} \mathrm{C}=\mathrm{CH}-\mathrm{Si}\left(-\mathrm{OCH}_{3}\right)_{3}$ (VTMS) and n-octyltriethoxysilane $\mathrm{CH}_{3}-\left(\mathrm{CH}_{2}\right)_{7}-\mathrm{Si}\left(-\mathrm{OC}_{2} \mathrm{H}_{5}\right)_{3}$ (OTES) - as the corrosion inhibitors of zinc.

To obtain a concentrated solution of SDDP, a dodecylphosphonic acid powder (Alfa Aesar, $95 \%$ ) was dissolved in distilled water by heating to $90^{\circ} \mathrm{C}$ and stirring, then neutralized with $\mathrm{NaOH}$ in a molar ratio of $1: 2$. VTMS and OTES were dissolved in ethyl alcohol. Alcoholic solutions of silanes were diluted with distilled water to prepare working solutions 
with the required concentration and with an alcohol content of $10.0 \%$. The $\mathrm{pH}$ values were measured using an EXPERT-pH instrument.

\subsection{Sample preparation}

The protective layers were studied on smooth and laser textured zinc surfaces. In the first case, zinc samples $25 \times 15 \times 6 \mathrm{~mm}$ in size were polished with emery paper to a "mirror" shine, degreased with acetone, and kept in air for $30 \mathrm{~min}$ to form an oxide layer.

In the second case, to study the effect of zinc surface morphology on the properties of films formed in the presence of CI, the polished and degreased samples were subjected to laser treatment under ambient conditions using an XM-30 laser marker with the following parameters: $P=7.5 \mathrm{~W} ; \mathrm{v}=20 \mathrm{kHz} ; d=0.01 \mathrm{~mm} ; l=0.01 \mathrm{~mm} ; V=100 \mathrm{~mm} / \mathrm{s}$, where $P$ is the radiation power, $v$ is the radiation frequency, $V$ is the scanning speed, $\mathrm{d}$ is the laser beam diameter, and 1 is the distance between two adjacent linear trajectories. Laser scanning was performed by a grid. After laser treatment, the samples were cleaned by ultrasound in acetone for $60 \mathrm{sec}$. to remove the particles formed that were weakly bound to the metal surface. After this preparation, the zinc surface acquired superhydrophilic properties. To make it hydrophobic, as well as to change the composition of the surface oxide layer, zinc samples were annealed for $1 \mathrm{~h}$ at $150^{\circ} \mathrm{C}$.

We have previously identified the optimal conditions for the treatment of zinc with SDDP and TAS in terms of the anticorrosion protection efficiency [29], therefore the prepared samples were kept sequentially in stirred solutions of $2.5 \mathrm{mM}$ SDDP and TAS at $40^{\circ} \mathrm{C}$. The concentrations of TAS solutions were $2.5,5.0$ and $10.0 \mathrm{mM}$. After that, the samples were dried for $1 \mathrm{~h}$ at $150^{\circ} \mathrm{C}$. The exposure time in each solution was $1 \mathrm{~h}$ with intermediate drying in air for $30 \mathrm{~min}$.

\subsection{Investigation of the protective properties of films pre-formed on zinc by SDDP and TAS}

\subsubsection{Electrochemical measurements.}

The electrochemical studies of the protective properties of films formed on zinc in CI solutions were carried out by the polarization (potentiodynamic) method. A two-key silver chloride electrode was used as the reference electrode. The measured electrode potentials were converted to the normal hydrogen scale. A pyrographite plate was used as the auxiliary electrode. All electrochemical measurements were carried out under static conditions at room temperature of the solution and with natural aeration.

Polarization measurements were performed in a borate buffer solution with $\mathrm{pH} 7.4$ containing $1 \mathrm{mM} \mathrm{NaCl}$, using an IPC-Pro MF potentiostat (Russia) with a potential scan rate of $0.002 \mathrm{~V} / \mathrm{s}$. The resistance of zinc coated with CI films to the corrosive action of chloride ions was evaluated by the difference of the local depassivation potentials, $\Delta E=E_{\mathrm{pt}}^{\mathrm{CI}}-E_{\mathrm{pt}}^{0}$, which were determined from the anodic polarization curves on samples without treatment $\left(E_{\mathrm{pt}}^{0}\right)$ and with preliminary modification with $\mathrm{CI}\left(E_{\mathrm{pt}}^{\mathrm{CI}}\right)$. 


\subsubsection{Corrosion tests}

The corrosion tests of zinc samples treated in solutions of SDDP and TAS were carried out in a heat and moisture chamber providing conditions of $100 \%$ humidity with periodic moisture condensation. The temperature mode of the heat and moisture chamber was as follows: the temperature was maintained at $40 \pm 2^{\circ} \mathrm{C}$ for $9 \mathrm{~h}$ a day, while the chamber was turned off for the rest of the day. The samples were prepared as described in section 2.2. Inspection of the samples was carried out at regular intervals from the beginning of the tests to determine the time until the appearance of the first corrosion damage $\left(\tau_{\mathrm{cor}}\right)$.

\subsection{Characteristics of the zinc surface modified with SDDP and TAS}

\subsubsection{Water contact angle measurements}

The hydrophobic properties of the protective layers on zinc formed in the presence of CI were evaluated by the value of the static contact angle $(\Theta)$ of a drop of distilled water. The $\Theta$ values were determined in the graphics editor Corel R.A.V.E. 2.0 from photographs of a water drop on the surface being studied, obtained using a laboratory unit with an integrated DCM300 camera. The drop volume was $20 \mu \mathrm{l}$ in each measurement. To obtain reliable information about the surface wettability, the measurements of $\Theta$ were carried out no later than 5-10 s after the drop was planted, at no less than 10 points of the surface. The standard deviation of $\Theta$ was $2.0-5.0^{\circ}$. The stability of the hydrophobic properties of the coatings obtained was estimated by the change in the $\Theta$ value with time during corrosion tests of samples in a heat and moisture chamber. Over time, the standard deviation increased to 7.0$9.0^{\circ}$ in some cases due to uneven degradation of the coatings.

\subsubsection{Zinc surface roughness measurement}

The roughness of the surface of zinc samples was estimated by the probe method using a Proton-MIET 130 profilograph. The study of the irregularities of the metal surface was carried out in several steps: the surface was "probed" a certain number of times with a diamond needle, then the averaged value of the parameters was calculated from a series of measurements. As a result of measurements, a record of the zinc surface profile and the roughness parameters were obtained: $R_{\mathrm{Z}}$ is the average height of irregularities at 10 points and $S$ is the average pitch of local protrusions in $\mu \mathrm{m}$.

\section{Results and discussion}

\subsection{Electrochemical behavior of zinc modified with SDDP and TAS}

An increase in the protective properties of phosphonate films obtained on zinc in an aqueous solution of SDDP by TAS of various structures, as well as some regularities in the formation of such phosphonate-siloxane coatings, were found by us previously [29]. In particular, the optimal conditions for the treatment of zinc with SDDP and TAS, in terms of the efficiency of anticorrosion protection, were determined and the advantages of layer-by-layer treatment 
with these CI compared to the passivation in their mixture was demonstrated. It was also shown that, when SDDP was used together with VTMS or OTES, films with the first layer of alkyl phosphonate had the best protective properties.

It is known that VTMS can reduce the dissolution rate of many metals and alloys, including zinc. However, it is most often used as an auxiliary additive, since it alone does not suppress corrosion completely [28, 34]. OTES molecules can form assembled layers on a metal surface due to a long hydrocarbon radical, thereby providing a barrier to the penetration of moisture and corrosive ions.

The polarization curves of zinc electrodes pre-passivated at various concentrations of solutions of SDDP with VTMS and OTES are shown in Figures 1a and 1b, respectively. The efficiency of joint passivation of zinc with SDDP and TAS was found to be higher than that by the individual CI. At the same time, the use of OTES in layer-by-layer treatment with an alkylphosphonate allows one to obtain coatings with better protective properties than in the case of VTMS. An increase in the concentrations of any of these TAS in solution to $10.0 \mathrm{mM}$ enhances the protective properties of the films thus obtained.
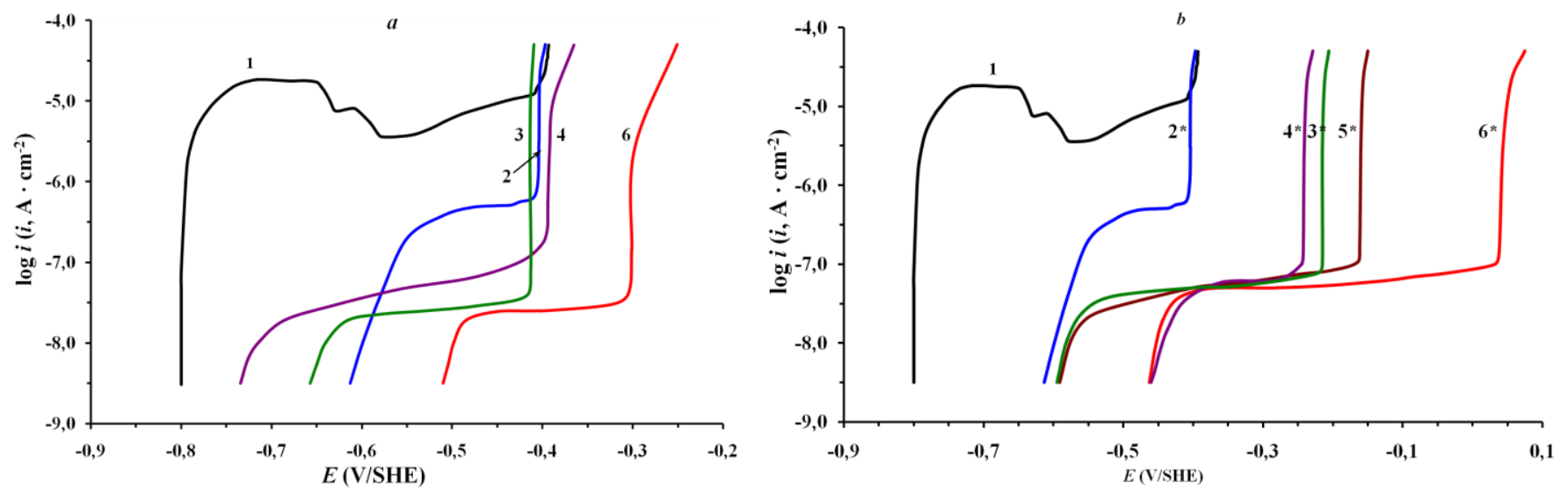

Figure 1. Anodic polarization curves of zinc in a borate buffer solution $(\mathrm{pH} \mathrm{7.4)}$ containing $1.0 \mathrm{mM} \mathrm{NaCl}$ without (1) and with preliminary layer-by-layer treatment in solutions of SDDP and TAS ( $\boldsymbol{a}$ - VTMS; $\boldsymbol{b}$ - OTES): $2,2 *-2.5 \mathrm{mM}$ SDDP; $\mathbf{3}, \mathbf{3}^{*}$ - $10.0 \mathrm{mM}$ TAS; $\mathbf{4}, \mathbf{4} *-2.5 \mathrm{mM}$ $\mathrm{SDDP} / 2.5 \mathrm{mM}$ TAS; 5, 5* $-2.5 \mathrm{mM}$ SDDP/5.0 mM TAS; 6 - $2.5 \mathrm{mM}$ SDDP/10.0 mM TAS.

The greatest $E_{\mathrm{pt}}$ shift of a zinc electrode in the positive direction is observed upon its layer-by-layer passivation in $2.5 \mathrm{mM}$ aqueous solution of SDDP and in $10.0 \mathrm{mM}$ aqueousalcoholic solution of OTES: $\Delta E=0.450 \mathrm{~V}$ (Figure 1b). This indicates the formation of more perfect films on the zinc surface, probably due to both chemisorption of the first alkylphosphonate layer and formation of a less defective and more stable upper siloxane layer as a result of lateral interactions between OTES molecules in it (horizontal siloxane bonds, van der Waals interactions between alkyl chains). 
3.2 Effect of laser treatment of zinc surface on the hydrophobic and protective properties of layers formed in the presence of SDDP and TAS

The air-oxidized zinc surface is hydrophilic and is characterized by $\Theta=72 \pm 3^{\circ}$. Treatment of zinc in solutions of SDDP with TAS hydrophobizes it surface, which, along with strong chemisorption of the alkylphosphonate [21], favors an increase in its corrosion resistance under the conditions studied. At joint use of SDDP with VTMS or OTES, the measured $\Theta$ values are slightly higher than in the case of passivation by these compounds alone. However, even upon layer-by-layer treatment of a smooth zinc surface with SDDP and OTES, the most hydrophobic of the silanes studied, the $\Theta$ value does not exceed $106 \pm 4^{\circ}$ (Table 1) [29].

Table 1. Contact angles $(\Theta)$ and images of water droplets on smooth and textured surfaces of zinc samples passivated in solutions of SDDP and TAS.

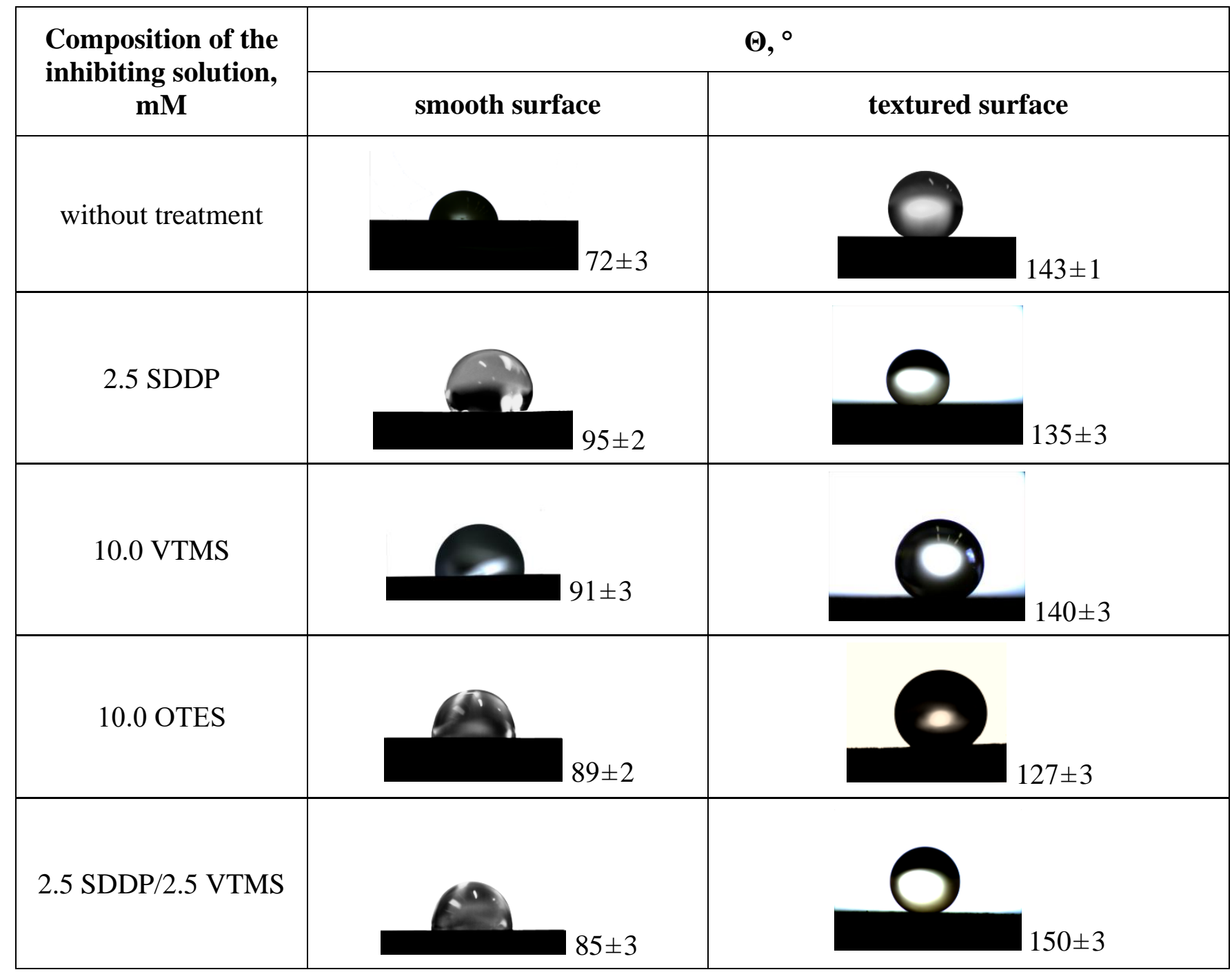




\begin{tabular}{|c|c|c|}
\hline \multirow{2}{*}{$\begin{array}{c}\text { Composition of the } \\
\text { inhibiting solution, } \\
\text { mM }\end{array}$} & \multicolumn{2}{|c|}{$\Theta,{ }^{\circ}$} \\
\hline & smooth surface & textured surface \\
\hline \multicolumn{3}{|l|}{$2.5 \mathrm{SDDP} / 10.0 \mathrm{VTMS}$} \\
\hline \multicolumn{3}{|l|}{ 2.5 SDDP/2.5 OTES } \\
\hline 2.5 SDDP/10.0 OTES & & \\
\hline & $106 \pm 4$ & $162 \pm$ \\
\hline
\end{tabular}

To obtain a superhydrophobic coating on zinc and hence to increase its corrosion resistance, the surface was laser treated with subsequent heating according to the procedure described in Section 2.2, after which it turned black. The nature of this phenomenon on various metals was studied in $[35,36]$. The authors of these works obtained "black velvet" multifunctional surfaces of brass, platinum, titanium and its alloy with nickel by producing hierarchical nano/microstructures by femtosecond laser pulses. Such surfaces had lightabsorbing, superhydrophobic, and self-cleaning properties. According to the results of chemical analysis by X-ray photoelectron spectroscopy, the blackening of metal surfaces is not associated with a change in the elemental composition. SEM studies of the morphology of surfaces structured by laser radiation showed the presence of coral-like surface structures consisting of micro-cavities with random orientations and protrusions that can be considered as conglomerates of nanoparticles expelled from ablation craters. The resulting microcavities and protrusions greatly increase the area of the metal surface, and the high degree of roughness makes these structures a porous light absorber owing to which the surface acquires a jet black color.

Indeed, our profilometry results demonstrate an increase in zinc surface roughness after laser treatment, while the $R_{\mathrm{z}}$ value increases more than 50-fold (Table 2). In this case, the surface becomes superhydrophilic, which is confirmed by the rapid and complete spreading of a water drop. Subsequent heating for $1 \mathrm{~h}$ at $150^{\circ} \mathrm{C}$ gives it hydrophobic properties $\left(\Theta=143 \pm 1^{\circ}\right)$, although it somewhat decreases the average height of the profile irregularities. As shown in $[32,33,37,38]$, this preparation of the metal surface gives it microstructural roughness and changes the composition of the oxide layer. This is due to the ablation and subsequent deposition of nanoparticles formed in the plasma onto the treated surface during laser treatment. Presumably, subsequent heating at $150^{\circ} \mathrm{C}$ increases the fraction of $\mathrm{ZnO}$ in 
the surface layer, while the $\mathrm{Zn}(\mathrm{OH})_{2}$ component practically disappears, as a result of which the morphology of the zinc surface changes with formation of dense small nanospheres consisting of $\mathrm{ZnO}$, which can serve as chemisorption centers for the CI.

Despite the high hydrophobic properties, the textured zinc surface quickly begins to corrode in a humid atmosphere: $\tau_{\text {cor }}=17 \mathrm{~h}$, which is only slightly longer than in the case of a smooth surface. The adsorption of SDDP or TAS themselves on such surface enhances its hydrophobicity, increasing the $\Theta$ value by $38-49^{\circ}$ in comparison with the smooth surface modified with the CI. A superhydrophobic coating on zinc with surface laser preparation was obtained only by layer-by-layer treatment in an SDDP solution with any of the silanes studied (Table 1). The greatest value of $\Theta\left(162 \pm 3^{\circ}\right)$ is observed in the case of the joint use of SDDP and OTES.

Table 2. Surface roughness parameters of zinc samples before and after laser and heat treatments.

\begin{tabular}{|c|c|c|c|}
\hline Treatment mode & $R_{\mathrm{z}}, \mu \mathrm{m}$ & $\boldsymbol{S}, \mu \mathrm{m}$ & Profilogram of surface roughness \\
\hline $\begin{array}{c}\text { without treatment } \\
\text { (smooth surfaces) }\end{array}$ & 0.91 & 1.89 & 13.35 \\
\hline $\begin{array}{c}\text { laser treatment } \\
\text { laser and heat } \\
\text { treatment }\end{array}$ & 54.85 & 12.27 & \\
\hline
\end{tabular}

The results of corrosion tests in a humid atmosphere of a heat and moisture chamber showed that the films obtained on a textured zinc surface during layer-by-layer treatment in solutions of SDDP and TAS are significantly superior in protective properties to films formed on a smooth surface. The inhibiting efficiency of the latter was studied earlier by us [29]. Both on smooth and textured zinc surfaces the layer-by-layer passivation by SDDP with OTES allows one to obtain coatings with better protective properties than with VTMS. The first corrosion damage on samples with such superhydrophobic coatings appears only after $773 \mathrm{~h}$, which is almost twice as much as with the same treatment of a smooth surface by CI (Figure 2). Thus, the layer-by-layer passivation of zinc in solutions of $2.5 \mathrm{mM}$ SDDP and $10.0 \mathrm{mM}$ OTES with preliminary laser treatment increases its corrosion resistance under severe conditions of $100 \%$ humidity almost 65 -fold. Apparently, in the presence of a more hydrophobic OTES with a relatively long alkyl, a stable highly ordered siloxane layer, which 
is capable of blocking existing defects in the film formed by a chemisorbed alkylphosphonate, is formed on the zinc surface.

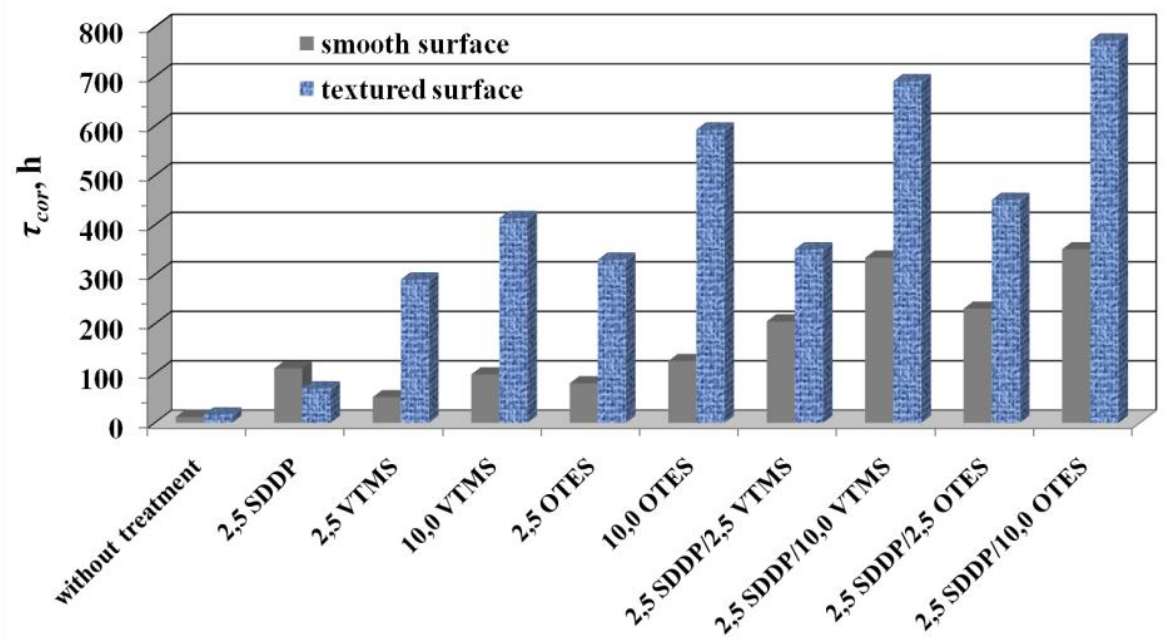

Figure 2. Time until the appearance of the first corrosion damage $\left(\tau_{\text {cor }}\right)$ in the heat and moisture chamber on zinc samples passivated in SDDP and TAS solutions, with and without preliminary laser preparation. The $\mathrm{CI}$ concentrations are given in $\mathrm{mM}$.

\subsection{Stability of hydrophobic properties of phosphonate-siloxane coatings on zinc}

In terms of the efficiency of superhydrophobic coatings and the possibilities of practical application, their ability to maintain their properties under operating conditions is important. Evaluation of the coating degradation, i.e., of the loss of hydrophobic properties, which we carried out during corrosion tests in a chamber of heat and moisture, showed that they were more stable upon layer-by-layer formation in SDDP and VTMS or OTES solutions than in the case of individual CIs. The coating obtained on a textured surface in a $2.5 \mathrm{mM}$ aqueous solution of SDDP quickly loses its hydrophobic properties (Figure 3). The zinc surface treated in $10.0 \mathrm{mM}$ aqueous-alcoholic solutions of VTMS or OTES retained high hydrophobic properties for more than $750 \mathrm{~h}$ of tests in a humid atmosphere even after the first corrosion damage appeared. It is important to note the tendency that the $\Theta$ value changes for a zinc sample with a film formed in the presence of OTES. In this case, the surface hydrophobicity significantly increases during the initial period, and a superhydrophobic state is almost reached after $250 \mathrm{~h}$ of testing $\left(\Theta=148^{\circ}\right)$. Apparently, it is due to the continuing self-assembly of OTES molecules in the siloxane film due to long hydrocarbon radicals. 


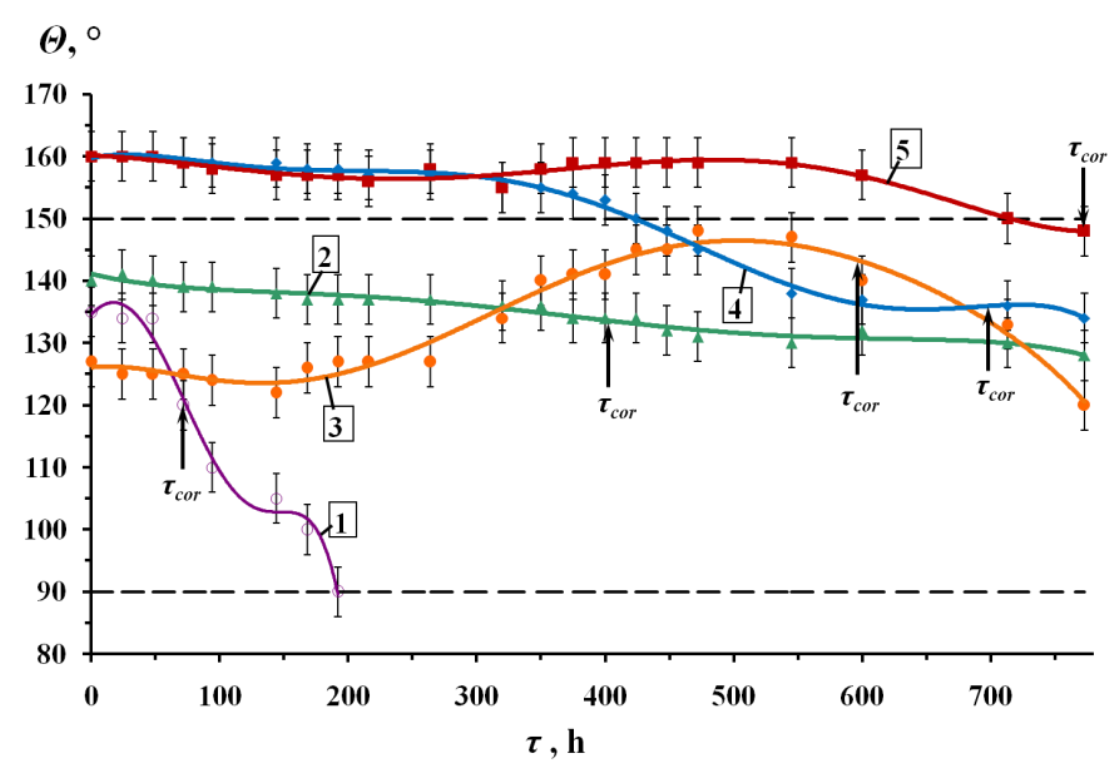

Figure 3. Change in the contact angle $(\Theta) v s$. time $(\tau)$ on textured surfaces of zinc samples after layer-by-layer treatment in solutions: 1 - 2.5 mM SDDP; 2 - 10.0 mM VTMS; 3 10.0 mM OTES; 4 - 2.5 mM SDDP/10.0 mM VTMS; 5 - 2.5 mM SDDP/10.0 mM OTES.

Layer-by-layer passivation of a laser textured zinc surface in solutions of SDDP and VTMS or OTES allows one to obtain coatings with high stability of superhydrophobic properties in a humid atmosphere. Apparently, the surface morphology obtained by laser and heat treatments provides better adhesion of the first phosphonate layer. In combination with a strong siloxane network in the top layer, this determines the high protective and hydrophobic properties of the coatings and their stability over time. The use of OTES together with SDDP is the most efficient, because even after $713 \mathrm{~h}$ of corrosion tests, the surface continues to be superhydrophobic, $\Theta=150 \pm 4^{\circ}$. The degradation of such film is nonuniform. As a result, local corrosion damage is observed on the samples even while maintaining superhydrophobic properties on the major part of the surface.

\section{Conclusions}

1. A method for the preparation of superhydrophobic coatings on a zinc surface by laser treatment followed by layer-by-layer chemisorption of alkylphosphonate and TAS is suggested.

2. The polymodal roughness of the zinc surface obtained due to laser and heat treatments allows one to achieve its superhydrophobization by layer-by-layer passivation with SDDP and TAS and to increase the protective properties of the thin films they form.

3. The most efficient variant involves layer-by-layer passivation of zinc in SDDP and OTES solutions with preliminary laser and heat treatment of the surface, which allows one to obtain resistant coatings with high protective and hydrophobic properties in a humid atmosphere with daily moisture condensation on the surface. 


\section{References}

1. Yu.I. Kuznetsov, Organic inhibitors of corrosion of metals, New York, Plenum Press, 1996, 283.

2. G.V. Lisichkin, A.Yu. Fadeev, A.A. Serdan, P.N. Nesterenko, P.G. Mingalev and D.B. Furman, Chemistry of surface grafted compounds, Moscow, Fizmatlit, 2003, 592 pp. (in Russian).

3. K. Aramaki and T. Shimura, Self-assembled monolayers of carboxylate ions on passivated iron for preventing passive film breakdown, Corr. Sci., 2004, 46, 313-328. doi: $10.1016 / \mathrm{S} 0010-938 \mathrm{X}(03) 00156-2$

4. M.G.S. Ferreira, R.G. Duarte, M.F. Montemor and A.M.P. Simoes, Silanes and rare earth salts as chromate replacers for pre-treatments on galvanized steel, Electrochim. Acta, 2004, 49, 2927-2935. doi: 10.1016/j.electacta.2004.01.051

5. P.G. Mingalyov and G.V. Lisichkin, Chemical modification of oxide surfaces with organophosphorus (V) acids and their esters, Russ. Chem. Rev., 2006, 75, 541-557. doi: 10.1070/RC2006v075n06ABEH002478

6. Yu.I. Kuznetsov, Organic corrosion inhibitors: where are we now? A review. Part II. Passivation and the role of chemical structure of carboxylates, Int. J. Corros. Scale Inhib., 2016, 5, no. 4, 282-318. doi: 10.17675/2305-6894-2016-5-4-1

7. Yu.I. Kuznetsov, Organic corrosion inhibitors: where are we now? A review. Part IV. Passivation and the role of mono- and diphosphonates, Int. J. Corros. Scale Inhib., 2017, 6, 384-427. doi: 10.17675/2305-6894-2017-6-4-3

8. W.E.G. Hansal, S. Hansal, M. Pflzler, A. Kornherr, G. Zifferer and G.E. Nauer, Investigation of polysiloxane coatings as corrosion inhibitors of zinc surfaces, Surf. Coat. Tehnol., 2006, 200, 3056-3063. doi: 10.1016/j.surfcoat.2005.01.049

9. P.J. Hotchkiss, M. Malicki, A.J. Giordano, N.R. Armstrong and S.R. Marder, Characterization of phosphonic acid binding to zinc oxide, J. Mater. Chem., 2011, 21, 3107-3112. doi: 10.1039/C0JM02829K

10. E. Hoque, J.A. DeRose, P. Hoffmann, B. Bhushan and H.J. Mathieu, Alkylperfluorosilane self-assembled monolayers on aluminum: A comparison with alkylphosphonate self-assembled monolayers, J. Phys. Chem. A, 2007, 111, 3956-3962. doi: 10.1021/jp066101m

11. I. Felhősi, J. Telegdi, G. Pálinkas, E. Kálmán, Kinetics of self-assembled layer formation on iron, Electrochim. Acta, 2002, 47, 2335-2340. doi: 10.1016/S0013-4686(02)00084-1

12. Yu.I. Kuznetsov, A.A. Chirkunov, A.S. Gorbachev and N.P. Andreeva, Passivation of mild steel by sodium octylphosphonate in neutral aqueous solution, Int. J. Corros. Scale Inhib., 2017, 6, 318-332. doi: 10.17675/2305-6894-2017-6-3-7

13. I. Milošev, M. Metikoš-Huković and Ž. Petrović, Influence of preparation methods on the properties of self-assembled films of octadecylphosphonate on Nitinol: XPS and EIS studies, Mater. Sci. Eng., 2012, 32, 2604-2616. doi: 10.1016/j.msec.2012.08.010 
14. S. Attavara, M. Diwekara, M.R. Linfordb, M.A. Davisc and S. Blair, Passivation of aluminum with alkyl phosphonic acids for biochip applications, Appl. Surf. Sci., 2010, 256, 7146-7150. doi: 10.1016/j.apsusc.2010.05.041

15. GN 2.1.5.1315-03, "Maximum permissible concentrations (MPC) of chemicals in water of water objects of drinking and cultural-domestic water use" (in Russian).

16. SanPiN 2.1.5.980-00, "Hygienic requirements for surface water protection" (in Russian).

17. F. Sinapi, L. Forget, J. Delhalle1 and Z. Mekhalif, Formation and characterization of thin films of $\mathrm{H}\left(\mathrm{CH}_{2}\right) \times \mathrm{PO}(\mathrm{OH})_{2}$ on polycrystalline zinc substrates, Surf. Interface Anal., 2002, 34, 148-154. doi: 10.1002/sia.1272

18. A.A. Chirkunov, A.S. Gorbachev, Yu.I. Kuznetsov and Kh.S. Shikhaliev, Inhibition of anodic dissolution of low-carbon steel with alkylphosphonates in a borate buffer solution, Prot. Met. Phys. Chem. Surf., 2012, 48, 769-772. doi: 10.1134/S2070205112070040

19. Yu.I. Kuznetsov, G.V. Red'kina and N.P. Andreeva, Adsorption from neutral solutions of sodium alkyl phosphonates on zinc and its passivation, Russ., J. Phys. Chem. A, 2018, 92, 2548-2555. doi: 10.1134/S0036024418120269

20. E.K. Mioč, Z.H. Gretič and H.O. Čurkovič, Modification of cupronickel alloy surface with octadecylphosphonic acid self-assembled films for improved corrosion resistance, Corros. Sci., 2018, 134, 189-198. doi: 10.1016/j.corsci.2018.02.021

21. G.V. Redkina, Yu.I. Kuznetsov, N.P. Andreeva, I.A. Arkhipushkin and L.P. Kazansky, Features of zinc passivation by sodium dodecylphosphontate in a neutral aqueous solution, Corros. Sci., 2020, 168. doi: $10.1016 /$ j.corsci.2020.108554

22. W. Yuan and W.J. van Ooij, Characterization of organofunctional silane films on zinc substrates, J. Colloid Interface Sci., 1997, 185, 197-209. doi: 10.1006/jcis.1996.4604

23. M.F. Montemor, A.M. Simões, M.G.S. Ferreira, B. Williams and H. Edwards, The corrosion performance of organosilane based pre-treatments for coatings on galvanized steel, Prog. Org. Coat., 2000, 38, 17-26. doi: 10.1016/S0300-9440(99)00080-6

24. L. Li, Yu. Zhang, J. Lei, J. He, R. Lv, N. Li and F. Pan, A facile approach to fabricate superhydrophobic Zn surface and its effect on corrosion resistance, Corr. Sci., 2014, 85, 174-182. doi: 10.1016/j.corsci.2014.04.011

25. M.A. Petrunin, N.A. Gladkikh, M.A. Maleeva, L.B. Maksaeva and T.A. Yurasova, The use of organosilanes to inhibit metal corrosion, Int. J. Corros. Scale Inhib., 2019, 8, no. 4, 882-907. doi: 10.17675/2305-6894-2019-8-4-6

26. A.M. Semiletov, Protection of aluminium alloys from atmospheric corrosion by thin films of inhibitors. Int. J. Corros. Scale Inhib., 2017, 6, no. 4, 449-462 doi: 10.17675/2305-6894-2017-6-4-5

27. A.M. Semiletov, A.A. Chirkunov and Yu.I. Kuznetsov. Protection of alloy AD31 from corrosion by adsorption layers of trimethoxysilanes and stearic acid, Mater. Corros., 2019, 71, no. 1, 77-85. doi: $10.1002 /$ maco.201911000 
28. M.A. Petrunin, L.B. Maksaeva, N.A. Gladkikh, E.N. Narkevich, T.A. Yurasova, A.A. Rybkin, E.V. Terekhova, V.A. Kotenev, E.N. Kablov and A.Yu. Tsivadze, The effect of vinyl-siloxane nanolayers on the corrosion behavior of zinc, Prot. Met. Phys. Chem. Surf., 2018, 54, 795-803. doi: 10.1134/S2070205118040123

29. G.V. Redkina, A.S. Sergienko and Yu.I. Kuznetsov, Two-stage zinc passivation by solutions of sodium dodecylphosphonate and trialkoxysilanes, Korroz.: Mater., Zashch. (Corrosion: Materials, Protection), 2020, 12 (in press)

30. I.N. Zavestovskaya, Laser nanostructuring of materials surface, Quantum Electron., 2010, 40, no. 11, 942-954. doi: 10.1070/QE2010v040n11ABEH014447

31. L. Ma, L. Wang, Ch. Li, J. Guo, P. Shrotriya, C. Deng and J. Zhao, Hybrid nanosecond laser processing and heat treatment for rapid preparation of super-hydrophobic copper surface, Metals, 2019, 9, 668. doi: 10.3390 / met9060668

32. D. Wei, J. Wang, H. Wang, Ya. Liu, Sh. Li and D. Li, Anti-corrosion behavior of superwetting structured surfaces on Mg-9Al-1Zn magnesium alloy, Appl. Surf. Sci., 2019, 483, 1017-1026. doi: 10.1016/j.apsusc.2019.03.286

33. L.B. Boinovich, A.M. Emelyanenko, A.D. Modestov, A.G. Domantovsky and K.A. Emelyanenko, Synergistic effect of superhydrophobicity and oxidized layers on corrosion resistance of aluminum alloy surface textured by nanosecond laser treatment, ACS Appl. Mat. Interfaces, 2015, 7, 19500-19508. doi: 10.1021/acsami.5b06217

34. N. Gladkikh, Yu. Makarychev, A. Chirkunov, A. Shapagin, M. Petrunin, L. Maksaeva, M. Maleeva, T. Yurasova and A. Marshakov, Formation of polymer-like anticorrosive films based on organosilanes with benzotriazole, carboxylic and phosphonic acids. Protection of copper and steel against atmospheric corrosion, Prog. Org. Coat., 2020, 141. doi: $10.1016 /$ j.porgcoat.2020.105544

35. Y. Yang, J. Yang, Ch. Liang, and H. Wang, Ultra-broadband enhanced absorption of metal surfaces structured by femtosecond laser pulses, Opt. Express, 2008, 15, 1126011265. doi: 10.1364/OE.16.011259

36. A.Y. Vorobyev and Ch. Guo, Multifunctional surfaces produced by femtosecond laser pulses, J. Appl. Phys., 2015, 117, 033103-1-033103-5. doi: 10.1063/1.4905616

37. L.B. Boinovich and A.M. Emelyanenko, Hydrophobic materials and coatings: principles of design, properties and applications, Russ. Chem. Rev., 2008, 77, 583-600. doi: 10.1070/RC2008v077n07ABEH003775

38. B. Zhang, S. Lu, W. Xu and Yu. Cheng, Controllable wettability and morphology of electrodeposited surfaces on zinc substrates, Appl. Surf. Sci., 2016, 360, 204-214. doi: $\underline{10.1016 / \text { j.apsusc. } 2015.11 .083}$ 